\title{
Optimizing Production Planning and Environmental Assessment of Conformity with the Inventory Management Methods in Iran
}

\author{
Shahram Gilaninia (Corresponding author) \\ Department of Management, Astara Branch \\ Islamic Azad University \\ Astara, Iran \\ E-mail: gilani_sh45@yahoo.com \\ Mousa Rezvani \\ Department of Management, Astara Branch \\ Islamic Azad University \\ Astara, Iran \\ Seyyed Javad Mousavian \\ Department of Management, Astara Branch \\ Islamic Azad University \\ Astara, Iran \\ Seyed Aref Asli \\ Department of Public Management, Rasht Branch \\ Islamic Azad University \\ Rasht, Iran
}

Received: August 24, 2011

doi:10.5430/jms.v2n4p75
Accepted: September 29, 2011 Published: December 15, 2011

URL: http://dx.doi.org/10.5430/jms.v2n4p75

\begin{abstract}
Analysis of related factors in order of performance characteristics between environmental compliance planning and production planning method in the Institute of industrial paper manufacturing industries, the basic goal of this research has been. The researcher presented a conceptual model to the analysis of this question deals with the degree of environmental compliance plan and method of production planning needs through the organization and process what factors will help to improve performance? Made from the viewpoint of performance, only the production of a manufacturing system with improved control aspects of production activity (reduced work in process manufacturing, reducing waste of time, human resources, reducing waste of time and practical capacity of machinery, equipment and improving quality) will not improve. If the fit between the characteristics of production planning environment, the main program and scheduled production and four dimensions there is mentioned. Total System Performance (liquidity to inventory and products) will not increase, based on the main topics of this paper is formed between the rate of fitness increase production planning environment and planning materials and parts through the impact on the control activity production (due to strong interference factor on the relationship between management commitment to compliance and control of manufacturing activities) increased production and efficiency through the improvement of the system was functioning.
\end{abstract}

Keywords: Environment, Production, Materials Planning, Commitment, Production Activity Control. 


\section{Introduction}

Turbulent world is changing today's world, organizations to provide their main objectives survival, development and competition, the great need to use patterns have developed and in the absence of scientific knowledge and application of the results of them will disappear from the scene there. Authors, the whole system futurism, art and production management to a competitive weapon should be considered. Many experts believe that management decision makers and decision makers of produce little attention to the development of knowledge and its application in production systems that are given about his tenure and for this reason that their competitive capacity lost to organizations are converting passive. Today, the government factory for production planning and different methods are used, one of the methods used in the production system in the form of working methods is planning materials and parts. Since the organization of large volume of inventory value of assets allocated to it gives the wrong way if selected production planning, organization, due to shortage or surplus inventory and competitive power and profitability of their lost and destruction and degradation finds lead. Therefore management must be equipped with the tools to identify the precise characteristics of environmental planning and materials planning methods and components, a method to select and apply any losses that prevented and ability to respond to the changing environment have. Researchers claim that by providing an analytical model and test its accuracy in industrial paper manufacturing industries such tool available to managers in the industry will study. During this research by measuring and evaluating environmental fitness class production planning and materials planning methods and components, management commitment to the implementation of selected methods, providing level control objectives and activities of the production system performance, degree of effectiveness of each of the variables the whole system to analyze how these variables impact on industry performance has explained the study.

\section{Statement Problem Research}

A good way in a workstation may be a completely wrong way on other workstations, the world in different aspects of his management theory, and may experience a variety of patterns, each of these models the structure as their top model introduced with special prejudice that they defend. Practical experience and theoretical knowledge of the researcher led them to believe that necessarily has a new, complex and advanced methods and how the implementation of models used to explain itself or poor system performance is not optimal, but choosing the correct patterns and correct provided is the determinant. Outcome studies and a researcher views the question in his mind that created, it can be presented analytical model, and how this adaptation process, the effect on production control activities, and ultimately organizational performance can be drawn up to achieve the expected performance expanded? The other main question is how the degree of planning is and environment adaptive planning methods increased materials and parts to produce a lead over the program, planning and control model of production activities to improve performance? In this regard, most research conducted in the research literature have been described, how the effects of environmental factors and variables did not show the desired and descriptive aspects and have had the most applications of the model is not news, also in the systems studied also more productive since most attention has been focused on the efficiency of production. Therefore, appropriate answers questions posed by the author on her until a specific analytical models designed and tested with the appropriate field study the effect of each of the variables contained in models should explain.

\section{Important of Research}

In inventory planning and control in most areas of post production and operations management is emphasized so that the frequency has been said, the inventory or services in any production system they play a critical role, with proper planning and inventory control that including product, work in process manufacturing, raw materials and components are in balance can be taken step by building operations. One of the most valuable asset holdings of firms is almost $40 \%$ of total assets forms. Operations managers have long found there a suitable inventory control system is of crucial importance. During each manufacturing company of parts and raw materials to the company. Flow control is very important because the direct cost, revenue and ultimately company performance and the success or failure affects. Thus the importance and necessity of research on the subject of study is considered in two dimensions: first, a theoretical value that is fundamental, namely how to model the relationship between fundamental variables in the form of new and more complete than previous studies have shown, explaining will. And then so what other models to test the accuracy and authenticity was confirmed by its reach, it can be used as a practical and applied way in determining the selection and control of continuous production planning methods used. Intended to establish compliance by the model is done dynamically, leading to improved organizational performance will be.

\section{Research Objectives}

The main purpose of this study and explain how to analyze the effect of conformity between environment, production planning (product characteristics, demand and production process) and material requirements planning methods and 
components on the control of production activities and organizations is the final performance. Other objectives of the study are as follows:

1. An increased awareness and practical knowledge in various ways researchers plan to identify and analyze materials in various environments for planning materials and components.

2. Test identified a pattern, which could hold about fitness level, commitment level (deviation from the pattern of planning materials) expected performance levels to predict.

3. Application of the above model to enhance performance and remove hidden negative factors in the commitment and control of plant floor activities

4. Characteristics measure environmental compliance planning and programming methods and materials components.

5. Measurements and the dimensions constituting the control of production activities, including work in process manufacturing, quality, human resources, equipment and machinery is.

6. Effect of compliance on the control and production activities in the context of system performance.

7. To understand and predict the rate of intervention management commitment as a moderator variable on the strong model and discover ways to improve it.

\section{Background Research}

About the performance of industry and environmental effects of its production planning study does not significantly eyes and most academic research in MS and PhD have been focused on production efficiency, production efficiency, instead of considering the total output of the system optimization local focus has been. Academic studies abroad also planning to approach and interact with the environment is planning to join a limited number are ending. The result of this research is expressed as follows:

Bray and Hyyl and Krvdr, For example, cases in relation to the market imbalance between requirements, design and manufacturing process planning method to the implementation of the company affects the production function have been describing and Rvdbrg Lhagr, The value of the selection process Selection methods in program planning at various levels have been delivered. Newman and Asryd Haran through academic research, as have the companies can have high performance and what is not subject to this method for planning inventory which they used it should be adopted, the first method of environmental features should be adjusted. Krajvsky Gyang and Savaya. Of the same models and understandable definitions to diff] differences in environmental planning for material requirement planning and KANBAN systems have used. Patrick Johnson and Aaron Matson, the University Swedish university presented their research results to production and Conference Management Association American operations to production planning environment impact on selection of materials planning methods, the factory has the capacity and control descriptive and describes how these relations have. Thus, although research is mentioned somewhat related to the planning perspective and its relationship with environmental planning shall clear, but the most descriptive and the result was considered to provide models are applied, no, no use attitude systemic failure to provide practical models and weaknesses of the research model Their major failure is one of the Best Gilani in 2010. Control your inventory in the book states that the attitude of contingency planning in the selection methods of materials and parts inventory management is the most important functions. His books on management science optimization in 2011, states that choose appropriate methods for planning and inventory management to operations research methods to use.

\section{Conceptual Research Model}

The relationship between degree of compliance with environmental planning production planning methods and materials and parts performance of system model is shown below, the above analytical model of connecting research hypotheses are derived:

\section{$<$ Figure 1 about here $>$}

Com in the above analytical model as confounding variables that directly affect the model as transparent and objective is measured. But E1, E2, E3 as confounding variables are indirect effects through the functional equation is proved by using the variance design is controlled mechanism.

Analytical models mentioned above will, of conformity between environment, production planning and materials planning methods and components that influence top management commitment is placed in its implementation, can be controlled through the impact of production activities will lead to improved organizational performance. Analytical model is actually achieved in actual practice is that a system will increase when the method of planning materials and parts to suit production planning environment, with the support, loyalty and support management at all levels of the 
organization, time wasting by controlling activities reduce production .According to the above analytical model, pest control and yield production activity, endogenous variables and dependent variables of words (effect) have been considered and the method of variable rate adaptation planning and production planning environment, as exogenous variables role plays. Each of the variables in their analytical model as an independent functions are defined. Each flash of a direct functional parameters obtained from two variables are associated. Test each of these parameters are obtained coefficients of the power (intensity) correlation between linear combinations of existing features in the independent variable and dependent variable combination of linear features in each unit change in independent variable feature shows. (According to the conventional correlation method) In a functional model of the strength coefficient orientation effect on other variables is a variable. Obtained and confounding variables in each equation includes functional random measurement errors and the dependent or independent variables such errors scale measurements and weight or method variance is [8] Analysis of functional equations model the main data analysis methods for complex and extensive relationships in the model variables are involved. The analytical methods to analyze different variables mean that a structure based on the theory "and the interactive effects of time," the effect of variables on both shows. The combination of mathematical and statistical methodology of complex analysis and factor analysis in a way that operating systems have come together to complex phenomena and relationships in the variables of the study and analysis will be.

Also for the main hypotheses and how to contact each of the features found in secondary research hypotheses conventional correlation method used most frequently to have been made.

\section{The Main Research Hypothesis}

Compliance rates between environment characteristics and production planning and materials planning methods which parts of the effective control of production activities and is also supported by the management (top management commitment) will lead to improved performance.

\subsection{Subsidiary Hypotheses}

1. Increasing the level of conformity between environment, production planning and materials planning methods and devices led to increased efficiency of control activities are produced.

2. Increasing the level of management commitment to the methods of planning materials and parts on the relationship between $\mathrm{AD}$, PAC makes a positive impact.

3. Control efficiency increased activity led to increased production yield will be organized.

\subsection{Variables and Their Operational Definition}

- compliance rate between the medium and method of production planning and materials planning components (AD) to the degree of fitness characteristics of products, demand, and production processes with the same characteristics in planning methods and materials and components referred to in a five-interval scale From low to high by a standard questionnaire by the researcher measured is placed.

- level management commitment (com) to the foot of the classification level management planning principles and rules of procedure adopted by the Organization of materials and parts will be said and can be achieved through the following relationship:

$\mathrm{COM}=1-\{($ value of purchases out of the program)/ (Total value of purchases during the planning period) $\}$

- production activity control (PAC), principles and techniques used in short-term management planning, control and evaluation activity industrial production in an organization by controlling production activities are described. Harn and Brown, according to definition (APICS) essentially controls the production activity can be as long-term executive programs from mom and Planning Program materials and parts can be considered Control of production activities in four domains (work in process manufacturing, equipment and machinery, human resources, and quality) is done and to make operational and can measure the geometric mean cost of waste resulting from the operation relevant period as the percentage of non-performance or the result of subtracting a number of its average realized the efficiency and quantity of the mentioned axes can be measured.

This relationship is calculated as follows.

PAC=Production activity control efficiency

WIP $=$ Percent of the cost of wasted time, using the machinery cost

$\mathrm{EQ}=$ percent loss during the construction work

$\mathrm{Q}=$ Percent loss costs resulting from lack of quality 
MAN=percent loss resulting from the lack of human resources, time cost.

function (PF) system performance based on the geometric mean of the percentage growth rate of sales revenue or institution, rate of return on assets and net profit rate before tax (inflation by bleaching) in the period of the study will be measured. Relationship The math is as follows:

In this regard:

PF: performance

PF1: sales revenue growth rate

PF2: rate of return on assets

PF3: Net profit before tax rates are.

$P F=\sqrt[3]{P F 1 \times P F 2 \times P F 3}$

\subsection{Scope of Study}

Study to determine the exact scope of subject, time and place is one of the main things that can be achieved in order to solve problems and explore the extent of operations and financial limitations and human factors when conducted. Researcher with the work shows that different variables considered and controlled and has witnesses. Thus the territory of the three study views the territory as subject, spatial territory and the territory shall be considered when:

\subsubsection{Thematic Territory}

Environmental Planning and production of materials and parts requirements under the main systems of production and operations management and attitudes within a system is placed. This research is intended to yield the following proportion to the degree of importance between environmental characteristics and method of production planning and material requirements planning in parts of Iran to the paper industry deals. The importance of fitness through increased environmental and planning methods, management commitment to increasing and improving production control activities and improving performance are explained. Yet the study of matter and interaction in a system-oriented approach and too focused on a systems approach to management systems are in production planning and management framework material is located.

\subsubsection{Territory When}

Territory in terms of time of study all the time in 2006 for five years until 2011 and is considered part of the order to the data through questionnaires and part of the financial and accounting documents will be obtained when a particular territory can not see was considered.

Population study group of the industry has taken the paper with regard to control variables, including stability materials management, with activity during the past five years and production manager, materials planning and procurement are not replacing them, the type of technology production, as the sample have been studied.

\section{Research Methodology}

Study of two views taken into consideration and the two main objective methodologies shall follow the first observations and measurements that were obtained after the occurrence of scientific principles to follow, and providing an analytical step in the theoretical domain beyond is removed. Also, relationships between variables in the model with a new perspective and new are analysis. Second, the model presented here that usability has studied the industry, had applied aspects in solving the problems caused by choosing the correct method of planning materials and parts would be way decoder. Therefore, models and research related to the existing correlation between variables of frequency of use and brought to action research methodology is a method of correlation.

\subsection{Methods of Data Collection}

Collection method in research field is information regarding each of the variables contained in the following models have been collected:

Proportionality between the rate of environmental planning: (characteristics of product or products, demand and process) planning methods and materials and parts (corresponding to characteristics of production planning environment),a standardized questionnaire and interviews by the researchers refer to supplementary books and documents relating to purchases consistent with the program and out of the database of organizations in the study area has been documented time view Performance information: See also the database of financial management has been collected. 


\subsection{The Data Collection Tool (see documents, records and questionnaires)}

Data about study variables related to production activity control (percentage of cost and time wasted in the production capacity of human resources, equipment and machinery, the percentage of wasted labor costs during construction cost and the percentage loss in quality), management commitment (number of units , minus the ratio of total purchases with no plans to purchase) and performance (geometric mean growth rate of sales revenue Institute, rate of return on assets and net profit before tax rate) through direct observation documents public accounting and industrial sectors, manufacturing and control inventory will be collected. Information related to environmental compliance characteristics of production planning and materials planning methods and also parts of the conformity assessment questionnaires will be measured.

Subjects contained in the questionnaire along with the corresponding indices by performing a limited sampling of the visiting experts inside and outside the organization has become as standard. The main axes questioned and measured degree of compliance, including product features or products, production process and changes are requested. Each of the questions in the questionnaire to gauge the true indicator of degree of role satisfaction or dissatisfaction for those using the method shall play.

The questions related to five-year performance of each company in 2006 until 2011 was considered. Subjects characterized by medium-scale production planning and measuring the distance using a criterion of five "Likert" in recent research by "Patrick Johnson to measure satisfaction and dissatisfaction with material planning methods used to confirm and Management Association production and also has U.S. operations. for measuring compliance planning methods and materials with existing components Environmental characteristics of production planning has been used .

\section{Methods for Data Analysis in the Study is Process Follows}

1 - Descriptive statistics for classification, display and analysis of descriptive data collected and used to describe the primary indicators and diagrams related to shape variables will distribute.

2 - Use of inferential statistical methods to analyze performance of the studied organizations is recommended. Because researchers in these methods is the ability to test the main and subsidiary hypotheses and research found in the form of analytical models can be presented about the accuracy or inaccuracy to the results of research assumptions need to be attained.

3 - Analysis of functional relationships, namely discovering relationships between variables in the model using conventional correlation methods (to test secondary hypotheses) and the main hypothesis (research model) and calculated determination coefficients (R2) If accepted, the application of research has had a lot. Statistical software used also according to their capabilities, including SAS, SPSS and Minitab have.

\subsection{Summarize the Results of the Trial and Execution of Research}

Final results of more tests performed are presented:

It is a reminder that the size distribution of all forms of property-related variables contained in the research model using the X2 was investigated size distribution and shape were all normal specifications.

The first hypotheses computed by conventional correlations the first hypothesis derived from the analytical model, hypothesis test:

HO: Degree of compatibility between planning methods and materials production planning environment leading to increased Efficiency of production activities are not controlled.

H1: Degree of conformity between the methods and materials planning environment leading to increased production planning Efficiency of production activities are controlled.

(It is explained that the number of digits for each variable size is 50)

$$
\text { MAN1=1-MAN EQ1=1-EQ Q1=1-Q WIP1=1-WIP }
$$

Conventional couples (focal)

$\mathrm{AD}=.23666 \mathrm{P} 13+.42911 \mathrm{D} 22+.04283 \mathrm{P} 31+.23021 \mathrm{P} 32$

$\mathrm{PAC}=.47583 \mathrm{WIP} 1+.33130 \mathrm{Q} 1-.26154 \mathrm{EQ} 1+.53496 \mathrm{MAN} 1$

$\mathrm{R}=.8233 \quad \mathrm{R} 2=.678 \quad \mathrm{P}=.0$

Among couples: result obtained by conventional linear combination couples the first canonical correlation coefficient $\mathrm{R}=$. /8233 and the correlation intensity $\mathrm{R} 2=. / 678$, and $\mathrm{PV}=. / 00$ strong relationship with one another and have this 
relationship is positive, Thus we can conclude that the linear combination mentioned as the best pair and talk before and predictive models has been introduced by increasing the degree of compliance, performance and production control activities will increase.

The second hypothesis test calculated by the canonical correlation

The second hypothesis derived from the analytical model, hypothesis test:

HO: Increasing commitment to the implementation of management planning methods material relationship between the degree of compliance methods Environment and planning positive effect does not.

H1: Increasing commitment to the implementation of management planning methods material relationship between the degree of compliance methods Environment and planning makes a positive impact.

Linear coefficients obtained (canonical couples) and linear correlation between the two compounds in the second hypothesis

Conventional couples (focal) First:

$\mathrm{AD}=\mathrm{COM} . / 0964+\mathrm{P} 32 . / 31222-\mathrm{P} 31 . / 1891+\mathrm{D} 22 . / 49930+\mathrm{P} 13 . / 28760+\mathrm{MAN} . / 49993+\mathrm{EQ}=. / 25463 \mathrm{Q} 1$

- Q2. / 38474 +WIP1. $/ 45248$

$\mathrm{P}=. / 000 \quad \mathrm{R} 2=. / 7035 \quad \mathrm{R}=. / 8388$

Result obtained Among couples by conventional linear combination couples the first canonical correlation coefficient $\mathrm{R}=. / 8388$ and intensity correlationR2 $=. / 7036$ and $\mathrm{P}=0 / \quad 000$ a strong relationship with one another and have this relationship is positive, Also entering the management commitment variable coefficient linear combination of the two has increased, we can conclude that the linear combination mentioned as the best pair and predict patterns of pre-interview and presented by management commitment and involvement variable, model predictive capability will increase found.

First namely management commitment on the relationship between environmental variables and the degree of compliance methods affect production planning and the second is the positive effect.

Third hypotheses computed by canonical correlations (focal)

The third assumption of the analytical test is:

HO: Control efficiency of production activities lead to increased organizational performance is not:

H1: Control efficiency of production activities lead to increased organizational performance are Linear coefficients obtained (canonical couples) and linear correlation between the two compounds in the third hypothesis canonical couples (focal) First:

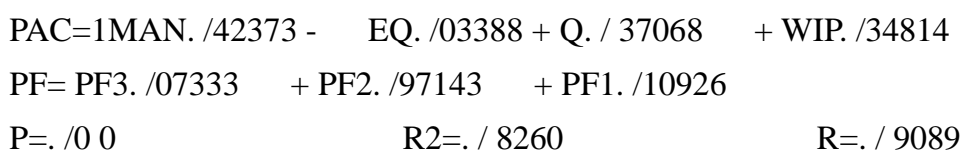

Result obtained lamong couples by conventional linear combination couples the first canonical correlation coefficient $\mathrm{R}=. / 9089$ and intensity correlation $\mathrm{R} 2=. / 8260$ and $\mathrm{P}=0 / 0$ a strong relationship with one another and have this relationship is positive, Therefore we can conclude that the linear combination mentioned as the best pair and talk and predict patterns before been presented with the control efficiency of production activities also will increase organizational performance.

\section{Conclusion}

A. Result of the first hypothesis (increased degree of compatibility between the characteristics of planning methods and properties of materials and components production planning environment leading to increased efficiency of control activities are produced), which clarifies what the compliance rate increased control efficiency of production activities in four domains, work in process manufacturing, quality, human resources and machinery equipment will increase as well.

B. Results from the second hypothesis (increased commitment to management practices in the field of planning methods and materials lead to strengthening the relationship between parts o methods and environmental compliance planning and control activities will be produced), which clarifies what level of management commitment different levels of planning methods and materials are more parts medium strength relationship between planning and programming methods will be more material. In other words the rate and intensity of management commitment on the level of performance and control related variables affect production activities. A result of the third hypothesis (control efficiency 
of production activities leading to improved organizational performance is) indicates that improving efficiency of production activity control four axes, which developed in line with the program is done, the organization will increase yield. The most important limitation of research problems and limitations in the research paper will be expressed as follows:

1 - Most institutions have studied a fully documented system for recording data related to work called in manufacturing, production stops due to lack of materials and parts as well as injuries resulting from lack of proper materials were not provided.

2 - Secrecy about sales, profitability rate and the rate of assets, obtaining such data can be associated with the problem.

3 - Low considered valuable to research planning methods related to materials and parts and also production planning in recognition of environmental organizations studied.

4 - Of qualitative research questionnaire data.

5 - Lack proper time for all the measures that a researcher should only fulfills.

6 - Recently, models and weak statistical software to test models of the potential limitations to the complex model was considered, the researcher inevitably that the assistance from other professionals such as trends and mathematical statistics will lead.

7 - Lack of resources and theoretical research conducted in connection with his research subject be forced to creativity, the indirect outcome research studies to be working. Such a process done by spending a long time and has been associated.

8 - No study by the University of Payments in other words Non-financial Support given the high cost of research, this research could make it consistent with the failures. As a major outlet for what a study should be considered, certainly getting the results and recommendations in line with scientific and practical assumptions are confirmed. And applied scientific research to provide guidelines for practical reasons, the managers of organizations will have higher priority. Managers learn by being involved in practical research results about the system the ability to identify and find your office in a member recommendations arose from the results acquired this important step will be taken to improve organizational performance. Based on results from the first research hypothesis is suggested: To identify characteristics of a production planning environment was acting according to these characteristics planning methods and materials appropriate parts selection. B constant adaptation method for controlling parts and materials planning environment as production planning data collected in the model and be documented Based on research results from the second hypothesis is suggested: With increasing knowledge of managers at different levels in the organization are provided with the purchase, the importance of loyalty to the method of planning materials and parts to their commitment toward the organization planned to increase material. Based on research results from the third hypothesis is suggested Production and operations managers with a continuous control efficiency rate in the control axis towards the integration of production activities and fitness programs with methods and materials to ensure in this way improve performance. B to design and create the organization as part of the financial unit controller and recording data related to sales growth, profit rate when the inventory turnover rate when action is normally required. This section as the main part of a macro system will operate.

C. A mechanized system of a fabric that data obtained from performance data obtained from the implementation of previous recommendations as to have available simultaneously and under software consistent with a model approved the study. Necessary to analyze conducted and completed in this way provides a tool to manage the organization to manage the overall performance of recognition systems with the necessary changes in planning methods and materials and parts production and the main program or any of the other variables that may lead to reduced activity of organizational performance will be improved to create the necessary changes and effects can also view and analyze. The system as a continuous and efficient information systems while management is placed in service. Result of implementation of recommendations, the deficit or surplus inventory and thereby minimizes the costs resulting from a major organization that additional inventory or inventory loss due to lack of materials and parts are required and will destroy, for a certain and practical realization of it being such an important field of knowledge and coordination between managers of different organizations at different levels is essential. Practical suggestions for future research in any scientific research eventually led to not only be specific results were achieved, but new ideas and new questions will bring, this study also had to follow such recommendations, which are as follows:

- Design, implement and test the model presented in this research field in the present paper to other industries such as paper and cleaning industries, paper and paper activity for newspapers and others. 
- Design, implement and test the model mentioned in the paper industry, small and medium.

Implement and test research models consider the relationship between the original production schedule and adapt methods and materials planning and environmental components, and production planning.

- MPS adaptation effects on performance and PAC organization and process analysis and direct or indirect causal relationship between the MPS and organizational performance.

- Implement and test the model in other industries, the country's current paper and discovered unusual properties and functional differences in each industry model. (Selected Industries)

- Feasibility study as a model organization overall control software.

- Specialized studies in the field of production planning environment classified according to the precise features of the characteristics of the present thesis.

- Implementation of an experimental study in the effects of the model paper in one of the country's industry to evaluate proposals and determine the actual effectiveness achieved.

- Evaluate the effect of external environmental factors on the organization and its internal environment interaction model for PF, PAC, COM, AD, MPS as their effects in the form of an analytical model can be expressed.

- Evaluate the effect of management prevailing taste of success and failure in the organization methods Planning needs of selected materials and parts industries.

\section{References}

Alwan, S. M. \& Myrshfyy, N.(2010). Production Management, Institution Press Astan Quds Razavi, Mashhad, Summer, pp. 367.

Arbitration, F. \& Violets, H. V. (2011). Topics in modern production \& operations management. Publishing Industrial Management, Tehran, Summer, pp. 11.

Berry, W. L. \& Hill, T. (1992). Linking Systems to Strategy. International Journal Of Operations \& production management. Vol. 12, No.10. pp. 3-15. http://dx.doi.org/10.1108/01443579210017204

Gianque, W. C. \& Sawaya, W. J. (1992). Strategies for production Control. Production \& inventory management Journal. Vol.33, No.3. pp. 36-41.

Gilaninia. S. (2011). Optimization of management sciences. Katibeh gil publisher.

Gilaninia. S. (2011). Principal of inventory management katibeh gil publisher.

Harhen, J., Brwen, J. \& O'kelly M. (1984). Production activity control \& the new way of life, Production \& inventory management. Fourth Quarter, pp.73-85.

Harn, J. J. (2010). Production management systems, Ghazanfar Mehdi Translation, Publishing Science \& Technology, Tehran, pp. 8581

James L. R., Mulik, S. A. \&Brett, J. M. (1992). Causal Analysis: Assumption, Models \& Data, Studying organization: Innovation in Methodology. Sage publications, pp. 48

Jarvis, C.(2002). The management of inventory, [Online] Available: http://solbranel.Ac.uk/-jarvis /bola /operations /stock / /efs /htm.

Jonsson, S. \& Mattson, A. (2001). The implication of planning environments on the success of manufacturing planning \& control methods. Proceedings of the twelfth Annual Conference of the operations management society, POM.

Knowledge, Y. \& Mohammadi, Z. S. (2010). Production \& operations management strategies \& tactics. New edition, Tehran, Winter. pp. 261.

Krajewski, L., King, B., Ritzman, L. \& Wong, D. (1987). (Unspecified article title). Management Science. Vol. 33, NO.L. pp.39-57. http://dx.doi.org/10.1287/mnsc.33.1.39

Mattson, S. A. \& Produktion, S. (1999). Planning smiljoer och Planning smetoder (in Swedish). Malmo: peematron.

Newman, W. \& Sridharan, V. (1995). Linking Manufacturing \& control to the manufacturing Environment. planning Integrated Manufacturing system. Vol. 6, No.4. pp.36-42.

Olhager, J. \& Rudberg, M. (2000). Linking process Choice \& Manufacturing planning \& control systems. Working paper, WP-258, Linkoping: Department of production Economies, Linkoping institute of Technology. 
Schroeder, D. M., Congden, S. W. \& Gopinath, C. (1995). Linking competitive Strategy \& Manufacturing process Technology. Journal of Management Studies. Vol 32, NO.2. pp.163-189. http://dx.doi.org/10.1111/j.1467-6486.1995.tb00339.x

Vollmann. T., Berry, W. \& Whybark, C. (2002). Manufacturing planning \& control Systems. New York Irwin McGraw-Hill.

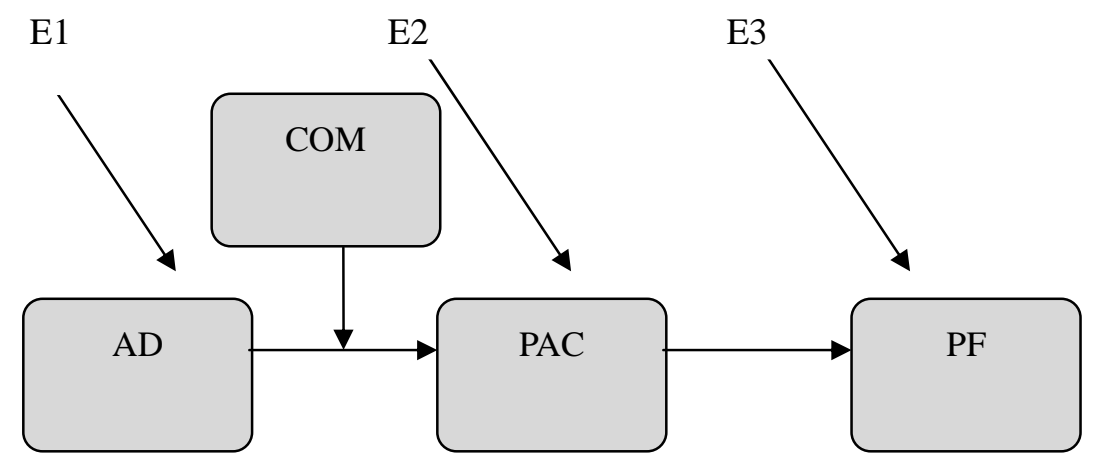

Figure 1. Analytical model for research 